\title{
An improved method to determine serine palmitoyltransferase activity
}

Rütti, M F ; Richard, S ; Penno, A ; von Eckardstein, A ; Hornemann, T

\begin{abstract}
Serine palmitoyltransferase (SPT) catalyzes the condensation of l-serine and palmitoyl-CoA, which is the rate-limiting step in the de novo synthesis of sphingolipids. SPT activity is commonly measured by monitoring the incorporation of radiolabeled l-serine into 3-ketodihydrosphingosine. In this article, we introduce several adaptations of the established protocol to improve sensitivity, reproducibility, and practicability of the assay. A significant improvement of this new protocol is the possibility to measure SPT activity in total cell lysate instead of microsomes. The assay is furthermore extended by the introduction of a nonradioactive, HPLC-based detection protocol. The suggested HPLC method offers several advantages, most importantly, a 20-fold lower detection limit compared with the radioactive assay and the possibility to use an internal standard to correct for variation in the extraction.
\end{abstract}

DOI: https://doi.org/10.1194/jlr.D900001-JLR200

Posted at the Zurich Open Repository and Archive, University of Zurich

ZORA URL: https://doi.org/10.5167/uzh-24512

Journal Article

Accepted Version

Originally published at:

Rütti, M F; Richard, S; Penno, A; von Eckardstein, A; Hornemann, T (2009). An improved method to determine serine palmitoyltransferase activity. Journal of Lipid Research, 50(6):1237-1244.

DOI: https://doi.org/10.1194/jlr.D900001-JLR200 


\title{
An improved method to determine serine palmitoyltransferase
}

\section{activity}

Markus F. Rütti, Stéphane Richard, Anke Penno, Arnold von Eckardstein, Thorsten Hornemann* Institute for Clinical Chemistry, University Hospital Zurich, Raemistrasse 100, CH-8091 Zurich, Switzerland

\begin{abstract}
Abbreviated title: Improved method to determine SPT activity
* To whom correspondence should be addressed at the Institute for Clinical Chemistry, OPS D 33, University Hospital Zurich, Raemistrasse 100, CH-8091 Zurich, Tel: 4144255 4719, Fax: 4144255 4590, e-mail: thorsten.hornemann@usz.ch
\end{abstract}

\section{Footnotes:}

The abbreviations used are: SPT, serine palmitoyltransferase; 3KDS, 3-ketodihydrosphingosine; OPA, ortho-phthalaldehyde; PyrDH, pyruvate dehydrogenase; SML, sucrose monolaurate; CerS, ceramide synthase; FB1, fumonisin $\mathrm{B}_{1}$; LOD, limit of detection 


\begin{abstract}
Serine palmitoyltransferase (SPT) catalyses the condensation of L-serine and palmitoyl-CoA, which is the rate-limiting step in the de novo synthesis of sphingolipids. SPT activity is commonly measured by monitoring the incorporation of radiolabeled L-serine into 3-ketodihydrosphingosine. In this article we introduce several adaptations of the established protocol to improve sensitivity, reproducibility and practicability of the assay. A significant improvement of this new protocol is the possibility to measure SPT activity in total cell lysate instead of microsomes. The assay is furthermore extended by the introduction of a non-radioactive, HPLC-based detection protocol. The suggested HPLC method offers several advantages, most importantly, a 20 -fold lower detection limit compared to the radioactive assay and the possibility to use an internal standard to correct for variation in the extraction.
\end{abstract}

Supplementary keywords: sphingolipids, HPLC 


\section{Introduction}

Serine palmitoyltransferase (SPT) [EC 2.3.1.50] catalyses the first, rate-limiting step in the de novo synthesis of sphingolipids - the condensation of palmitoyl-CoA and L-serine to 3ketodihydrosphingosine (3KDS) $(1,2)$.

Sphingolipids are bioactive metabolites and modulate the activities of various enzymes, such as protein kinases, protein phosphatases and phospholipases in cells or cell-free systems (3). They are involved in many cellular events including proliferation, differentiation, senescence, apoptosis and inflammatory responses (4). Abnormalities in the function of SPT cause clinical disorders, such as hereditary sensory neuropathy type I. $(5,6)$. Recent studies also indicate that human plasma sphingolipid levels are an independent risk factor for coronary artery disease (7) and that lowering sphingolipid levels by pharmaceutical interventions can reduce the risk for atherogenesis in apolipoprotein E-knockout mice (8). Other data indicate that sphingolipids are involved in the pathological aggregation of amyloid- $\beta$ fragments, which is a key process in the development of Alzheimers' disease (9).

To address these issues on a biochemical level a robust, sensitive and reproducible SPT activity assay would be desirable. SPT activity is usually determined by the method described by Merrill and Williams $(10,11)$, using $\left[{ }^{3} \mathrm{H}\right]-$ or $\left[{ }^{14} \mathrm{C}\right]-\mathrm{L}-$-serine as a substrate, or variants thereof.

In this work we looked at various aspects of this method and suggest several adaptations for simplification and to improve assay precision and sensitivity. We furthermore provide a protocol for a standardised SPT activity assay to improve reproducibility and inter-assay comparability.

\section{Experimental procedures}

All chemicals, unless otherwise stated, were purchased from Sigma-Aldrich (St. Louis, MO, USA). L-[U${ }^{14} \mathrm{C}$ ]-serine was from GE Healthcare (Little Chalfont, Buckinghamshire, UK). $\mathrm{C}_{17}$ - and $\mathrm{C}_{20}$-sphingosine were from Avanti Polar Lipids (Alabaster, AL, USA).

\section{Photometric assays}

Thioesterase activity was measured photometrically by monitoring the reaction of free CoA with DTNB at $412 \mathrm{~nm}$ in a spectrophotometer (12). Concentrations were determined with a molar absorption 
coefficient of $13.6 \mathrm{mM}^{-1} \mathrm{~cm}^{-1}$ for the 2-nitrobenzoate anion. The assay typically contained $50 \mu \mathrm{M}$ palmitoyl-CoA, $100 \mu \mathrm{M}$ DTNB and the corresponding amount of cells as stated in the text.

The influence of DTT on the release of free CoA from the substrate was determined enzymatically using pyruvate dehydrogenase (PyrDH). The assay contained $50 \mathrm{mM}$ HEPES (pH 8), $50 \mu \mathrm{M}$ palmitoyl-CoA, 1 $\mathrm{mU}$ PyrDH, $1 \mathrm{mM}$ sodium pyruvate, $2.5 \mathrm{mM}$ thiamine pyrophosphate, $2.5 \mathrm{mM} \mathrm{MgCl} 2,2.5 \mathrm{mM} \mathrm{NAD}^{+}$, $100 \mu \mathrm{M}$ NADH, $0.5 \mathrm{mg} / \mathrm{ml} \mathrm{BSA}, 50 \mathrm{mM}$ sodium oxamate (to inhibit the lactate dehydrogenase) and the corresponding amount of DTT. NADH oxidation was monitored spectrophotometrically at a wavelength of $340 \mathrm{~nm}$ using an absorption coefficient of $6.22 \mathrm{mM}^{-1} \mathrm{~cm}^{-1}$. Background reactions were monitored in control samples without palmitoyl-CoA.

Photometric assays were usually performed in a 96-well polystyrene flat-bottom microtiter plate (Nunc, Roskilde, Denmark) and measured using a microplate spectrophotometer (PowerWave 340, BioTek, Winooski, VT, USA).

\section{Sample preparation, SPT reaction and lipid extraction}

Human Embryonic Kidney cells (HEK293) were grown in DMEM supplemented with 10\% fetal calf serum, penicillin $\mathrm{G}(100 \mathrm{U} / \mathrm{ml})$ and streptomycin $(100 \mu \mathrm{g} / \mathrm{ml})$. Cultures were maintained at $37{ }^{\circ} \mathrm{C}$ in a $5 \%$ $\mathrm{CO}_{2}$ atmosphere at $100 \%$ humidity. Cell membrane microsomes were prepared as follows: A HEK293 cell monolayer in a 10-cm dish was washed twice with $3 \mathrm{ml}$ of PBS and suspended in $500 \mu 1$ of $50 \mathrm{mM}$ HEPES (pH 8) and $1 \mathrm{mM}$ EDTA. The cell suspension was sonicated for $15 \mathrm{~s}$ at $50 \%$ power and $50 \%$ pulsation (Sonopuls HD 2070, Bandelin, Berlin, Germany) and centrifuged at 2'500g for $2 \mathrm{~min}$. The supernatant was then centrifuged at $100^{\prime} 000 \mathrm{~g}$ for $30 \mathrm{~min}$ and the pellet was resuspended in the desired buffer (usually $50 \mathrm{mM}$ HEPES (pH 8) and $1 \mathrm{mM}$ EDTA). Preparation of total cell lysate, SPT reaction and lipid extraction were performed as described in the appendix. Protein determinations were performed according to Bradford (13), using the protein assay kit from BioRad (Hercules, CA, USA). For some experiments a prokaryotic, soluble form of SPT from Sphingomonas paucimobilis was used (14). The protein was expressed in Escherichia. coli (BL21 star (DE3)) using the pET expression system (pET21b, Invitrogen, Carlsbad, CA, USA) according to the manufacturer's protocol. Cells were lysed in $50 \mathrm{mM}$ HEPES (pH 8), $5 \mathrm{mM}$ EDTA by sonification and stored at $-20{ }^{\circ} \mathrm{C}$ in $50 \%$ glycerol. 


\section{Detection of radioactivity by liquid scintillation counting}

Radioactivity was determined using Ultima Gold (PerkinElmer, Wellesley, MA, USA) liquid scintillation cocktail and a Packard Tri-Carb 1900TR (PerkinElmer) scintillation counter.

\section{Product detection by high performance liquid chromatography (HPLC)}

The HPLC system consisted of a LC-10Ai solvent delivery module (Shimadzu, Kyoto, Japan), SIL10ADvp automatic injector (Shimadzu), SCL-10Avp system controller (Shimadzu) and a 1046A fluorescence detector (Hewlett-Packard, Palo Alto, CA, USA). Peaks were analysed and quantified with VP-CLASS (version 6.14 SP4).

\section{Results and discussion}

\section{Influence of DTT on palmitoyl-CoA stability}

The addition of DTT is considered to have a beneficial effect on SPT activity by protecting active site cystein residues from oxidation. However, the presence of DTT might also influence the stability of palmitoyl-CoA due to the reduction of the thioester bond in activated fatty acids. To determine the effect of DTT on substrate stability we incubated palmitoyl-CoA with DTT in concentrations from 0 to $10 \mathrm{mM}$. The DTT dependent release of free CoA is illustrated in Figure 1. DTT concentration of $5 \mathrm{mM}$, as it was suggested originally by Merrill and Williams $(10,11)$ did not significantly influence palmitoyl-CoA concentrations within 10 min of incubation. However, about $50 \%$ of the palmitoyl-CoA was reduced after $60 \mathrm{~min}$. This considerable reduction in substrate concentration has to be considered when performing the assay with longer incubation times. Although the presence of DTT might have a beneficial effect, we never observed a reduced SPT activity due to oxidation, even in samples which were stored up to 6 months at $-20^{\circ} \mathrm{C}$. Therefore we believe that the presence of DTT in the assay is not essential to maintain SPT activity. However, if DTT is desired, the concentration should be limited to $0.1-0.5 \mathrm{mM}$.

\section{Sample preparation and acyl-CoA thioesterases}

SPT activity is usually determined in microsomal preparations. This results in an improved specific activity of the enzyme since cytoplasmatic proteins are largely removed during the microsomal preparation. More important, the use of microsomes also reduces the number of interfering enzymes like 
acyl-CoA thioesterases or non-specific hydrolases which compete with the SPT for the substrate palmitoyl-CoA. However, the preparation of microsomes is time consuming, requires an ultracentrifuge and needs rather large amounts of tissue and cells. Furthermore, the resolubilisation of the pelleted microsomal membranes in the absence of a detergent is critical and results frequently in inhomogeneities of the membrane suspensions. The possibility to measure SPT activity directly in cell lysate would significantly simplify these preparative steps. However, the major obstacle for the use of cell lysate is the presence of highly active acyl-CoA thioesterases which results in a fast hydrolysation of the substrate palmitoyl-CoA (11). Acyl-CoA thioesterases are a ubiquitously expressed family of enzymes which show high activities in the cytosol of most eukaryotic cells. Their exact physiological role is not fully clear, but probably important to maintain appropriate intracellular levels of acyl-CoA, free CoA, and free fatty acids (15).

To reduce this perturbing background activity, we aimed to block the thioesterase activity without affecting SPT activity. Thioesterase activity is influenced by several detergents, some lipids and divalent ions like $\mathrm{Mn}^{2+}$ and $\mathrm{Ni}^{2+}$ (16-19). We investigated several substances in regard to their inhibitory effect on thioesterases and their interference with SPT activity. We found that sucrose monolaurate (SML) showed the best inhibitory effect on thioesterase activity without a detectable inhibitory effect on SPT activity (Table 1). The residual thioesterase activity in cell lysate with $0.1 \%$ SML was comparable to the thioesterase activity in microsomes (Figure 2A). SPT activity in microsomes was $50 \mathrm{pmol} / \mathrm{min} / \mathrm{mg}$, which is in the range of previously reported results (2.6 to $127 \mathrm{pmol} / \mathrm{min} / \mathrm{mg}$ in different rat tissues) $(11,20,21)$. SPT activity in total cell lysate without any additions was about 6 -fold lower. The addition of $0.1 \%$ SML significantly improved SPT activity and the activity was comparable to microsomes. In the presence of $0.1 \%$ SML the reaction was linear for up to $60 \mathrm{~min}$ (Figure 2B). Therefore the assay can be performed over a longer time span which leads to more product and an improved signal-to-noise ratio. The addition of $0.1 \%$ SML to the microsomal preparation did not further increase SPT activity.

A comparison of SPT activity in the various preparations of HEK293 cells is summarised in Table 1.

\section{Optimal substrate concentration}

The $\mathrm{K}_{\mathrm{m}}$ for L-serine was reported to be in the range of $0.1 \mathrm{mM}$ to $1.8 \mathrm{mM}$ for the mammalian SPT (11, 22-24). We re-determined $K_{m}$ and $V_{\max }$ with the new assay conditions (Figure 3). L-serine shows a 
regular Michaelis-Menten kinetics while palmitoyl-CoA shows an inhibitory effect at higher substrate concentrations. This substrate inhibition and was already reported earlier for the mammalian $(11,25,26)$ and for the plant enzyme (24). The maximum of activity was seen at a concentration of approx. 0.05-0.1 $\mathrm{mM}$ palmitoyl-CoA (Figure 3B). A $\mathrm{K}_{\mathrm{m}}$ of $1.2 \mathrm{mM}$ for L-serine was determined by an Eadie-Hofstee plot. This shows a rather low affinity of SPT towards its substrate L-serine. Commonly the SPT assay is performed at L-serine concentrations between 0.5 and $1 \mathrm{mM}$. This is far from saturating conditions which are required to measure enzyme activity at its maximal velocity $\left(\mathrm{V}_{\max }\right)$. However, increasing L-serine concentrations in the assay bears the disadvantage that also the amount of radioactive L-serine must be increased in order to maintain the specific radioactivity of the substrate. This is often unfavourable due to cost, health and security reasons. We therefore aimed to establish a non-radioactive, HPLC-based detection method to circumvent the need for radioactivity and to perform the assay under optimal substrate conditions. The used HPLC detection is based on the method of Riley and colleagues (27). Since 3KDS, as the direct product of the SPT reaction, cannot be efficiently detected with this method we converted the $3 \mathrm{KDS}$ chemically with sodium borohydride $\left(\mathrm{NaBH}_{4}\right)$ to sphinganine. This reaction is not stereospecific and results in the formation of erythro- and threo-sphinganine. These two products can be derivatised with ortho-phthalaldehyde (OPA) and quantified by HPLC (Figure 4). Total SPT activity is reflected by the sum of both diastereoisomers. In the negative control, SPT activity was specifically blocked by the addition of myriocin - a commonly used SPT inhibitor (28). Trace amounts of free sphinganine might also be found in the control extract, so that the net SPT activity is calculated by the difference between sample and control.

The detection by HPLC might be biased since the SPT product, 3KDS, could potentially get also acyltated by the ceramide synthase (CerS). The diacyl form of 3KDS would be not visible in the HPLC since the primary amine is blocked by the N-linked fatty acid and can not form a fluorescent derivate with OPA. To exclude this possibilitly, we performed the assay in the presence and absence of fumonisin $\mathrm{B}_{1}$ (FB1), a specific inhibitor of CerS (29). We found that the presence of FB1 had no influence on the detected sphinganine levels (data not shown).

The limit of detection (LOD) for the radioactivity- and HPLC-based method was compared. The LOD was defined as the activity for which the standard deviation exceeds $20 \%$. Under the chosen condition, the LOD for the HPLC-based detection was $0.1 \mathrm{pmol} / \mathrm{min}$ versus $2 \mathrm{pmol} / \mathrm{min}$ for the radioactive assay. 
This means that the detection limit of the HPLC-based method is about 20 times lower compared to the radioactive method.

However, both methods showed a very close correlation $\left(\mathrm{r}^{2}=0.9519\right)$ (Figure 5B). This demonstrates that the product determination by HPLC is as specific as the radioactive assay and not biased by the presence of an underlying metabolite which might be misinterpreted in the HPLC chromatogramm. A further important advantage of the HPLC-based detection is the possibility to add an internal standard to correct for variations in the preparative steps. We used $\mathrm{C}_{20}$-sphingosine or preferably $\mathrm{C}_{17}$-sphingosine, a nonnaturally occurring sphingoid base, as an internal standard. Although the HPLC-based method shows significant improvements in terms of sensitivity and variability, it is on the other hand more laborious and time consuming in comparison to the radioactive assay.

\section{Conclusions}

In this work we aimed to improve various aspects of the commonly used method to determine SPT activity. One of the major improvements is the possibility to measure activity directly in total cell lysate. We showed that the presence of $0.1 \%$ SML significantly inhibits the thioesterase background activity which interferes with the SPT activity measurements. Under these conditions, SPT activity in the total cell lysate was similar to that in microsomes. This adaptation allows it to perform the assay with significantly smaller amounts of tissue and cells. The addition of $0.1 \%$ SML also significantly improves the linearity of the reaction. In the presence of $0.1 \%$ SML, SPT activity was linear for up to 60 min which resulted in an improved signal-to-noise ratio. We furthermore identified a negative effect of DTT on the stability of palmitoyl-CoA and suggested to reduce or omit the addition of DTT to the assay. Finally, we introduced a non-radioactive, HPLC-based detection method, which makes it possible to measure SPT activity under saturating substrate concentration. This HPLC-based method shows a 20-fold lower detection limit in comparison to the radioactive detection.

We think that these adaptations lead to significant improvements in the robustness, sensitivity and reproducibility of the SPT assay. 


\section{Acknowledgments}

We would like to thank the Hartmann Müller Foundation, the Herzog-Egli Foundation, the EMDO

Foundation and the Foundation for scientific research (University of Zurich) for financially supporting this work. We also thank H. Kagamiyama for providing us with the expression plasmid of the soluble SPT from S. paucimobilis. 


\section{References}

1. Hanada, K. 2003. Serine palmitoyltransferase, a key enzyme of sphingolipid metabolism. Biochim Biophys Acta 1632: 16-30.

2. Merrill, A. H., Jr., and E. Wang. 1986. Biosynthesis of long-chain (sphingoid) bases from serine by LM cells. Evidence for introduction of the 4-trans-double bond after de novo biosynthesis of Nacylsphinganine(s). J Biol Chem 261: 3764-3769.

3. Hannun, Y. A., C. Luberto, and K. M. Argraves. 2001. Enzymes of sphingolipid metabolism: from modular to integrative signaling. Biochemistry 40: 4893-4903.

4. Hannun, Y. A., and L. M. Obeid. 2002. The Ceramide-centric universe of lipid-mediated cell regulation: stress encounters of the lipid kind. J Biol Chem 277: 25847-25850.

5. Bejaoui, K., C. Wu, M. D. Scheffler, G. Haan, P. Ashby, L. Wu, P. de Jong, and R. H. Brown, Jr. 2001. SPTLC1 is mutated in hereditary sensory neuropathy, type 1. Nat Genet 27: 261-262.

6. Dawkins, J. L., D. J. Hulme, S. B. Brahmbhatt, M. Auer-Grumbach, and G. A. Nicholson. 2001. Mutations in SPTLC1, encoding serine palmitoyltransferase, long chain base subunit-1, cause hereditary sensory neuropathy type I. Nat Genet 27: 309-312.

7. Jiang, X. C., F. Paultre, T. A. Pearson, R. G. Reed, C. K. Francis, M. Lin, L. Berglund, and A. R. Tall. 2000. Plasma sphingomyelin level as a risk factor for coronary artery disease. Arterioscler Thromb Vasc Biol 20: 2614-2618.

8. Park, T. S., R. L. Panek, S. B. Mueller, J. C. Hanselman, W. S. Rosebury, A. W. Robertson, E. K. Kindt, R. Homan, S. K. Karathanasis, and M. D. Rekhter. 2004. Inhibition of sphingomyelin synthesis reduces atherogenesis in apolipoprotein E-knockout mice. Circulation 110: 3465-3471.

9. Grimm, M. O., H. S. Grimm, A. J. Patzold, E. G. Zinser, R. Halonen, M. Duering, J. A. Tschape, B. De Strooper, U. Muller, J. Shen, and T. Hartmann. 2005. Regulation of cholesterol and sphingomyelin metabolism by amyloid-beta and presenilin. Nat Cell Biol 7: 1118-1123.

10. Merrill, A. H., Jr. 1983. Characterization of serine palmitoyltransferase activity in Chinese hamster ovary cells. Biochim Biophys Acta 754: 284-291.

11. Williams, R. D., E. Wang, and A. H. Merrill, Jr. 1984. Enzymology of long-chain base synthesis by liver: characterization of serine palmitoyltransferase in rat liver microsomes. Arch Biochem Biophys 228: $282-291$. 
12. Berge, R. K., and B. Dossland. 1979. Differences between microsomal and mitochondrial-matrix palmitoyl-coenzyme A hydrolase, and palmitoyl-L-carnitine hydrolase from rat liver. Biochem J 181: $119-125$.

13. Bradford, M. M. 1976. A rapid and sensitive method for the quantitation of microgram quantities of protein utilizing the principle of protein-dye binding. Anal Biochem 72: 248-254.

14. Ikushiro, H., H. Hayashi, and H. Kagamiyama. 2001. A water-soluble homodimeric serine palmitoyltransferase from Sphingomonas paucimobilis EY2395T strain. Purification, characterization, cloning, and overproduction. J Biol Chem 276: 18249-18256.

15. Hunt, M. C., and S. E. Alexson. 2002. The role Acyl-CoA thioesterases play in mediating intracellular lipid metabolism. Prog Lipid Res 41: 99-130.

16. Broustas, C. G., and A. K. Hajra. 1995. Purification, properties, and specificity of rat brain cytosolic fatty acyl coenzyme A hydrolase. J Neurochem 64: 2345-2353.

17. Lee, K. Y., and H. Schulz. 1979. Isolation, properties, and regulation of a mitochondrial acyl coenzyme A thioesterase from pig heart. J Biol Chem 254: 4516-4523.

18. Berge, R. K., and M. Farstad. 1979. Dual localization of long-chain acyl-CoA hydrolase in rat liver: one in the microsomes and one in the mitochondrial matrix. Eur J Biochem 95: 89-97.

19. Sanjanwala, M., G. Y. Sun, and R. A. MacQuarrie. 1987. Purification of long-chain acyl-CoA hydrolase from bovine heart microsomes and regulation of activity by lysophospholipids. Arch Biochem Biophys 258: 299-306.

20. He, X., X. L. Guan, W. Y. Ong, A. A. Farooqui, and M. R. Wenk. 2007. Expression, activity, and role of serine palmitoyltransferase in the rat hippocampus after kainate injury. J Neurosci Res 85: 423432.

21. Merrill, A. H., Jr., D. W. Nixon, and R. D. Williams. 1985. Activities of serine palmitoyltransferase (3-ketosphinganine synthase) in microsomes from different rat tissues. J Lipid Res 26: 617-622.

22. Holleran, W. M., M. L. Williams, W. N. Gao, and P. M. Elias. 1990. Serine-palmitoyl transferase activity in cultured human keratinocytes. J Lipid Res 31: 1655-1661.

23. Merrill, A. H., Jr., and E. Wang. 1992. Enzymes of ceramide biosynthesis. Methods Enzymol 209: 427-437. 
24. Lynch, D. V., and S. R. Fairfield. 1993. Sphingolipid Long-Chain Base Synthesis in Plants (Characterization of Serine Palmitoyltransferase Activity in Squash Fruit Microsomes). Plant Physiol 103: $1421-1429$.

25. Braun, P. E., and E. E. Snell. 1967. The biosynthesis of dihydrosphingosine in cell-free preparations of Hansenula ciferri. Proc Natl Acad Sci U S A 58: 298-303.

26. Merrill, A. H., Jr., and R. D. Williams. 1984. Utilization of different fatty acyl-CoA thioesters by serine palmitoyltransferase from rat brain. J Lipid Res 25: 185-188.

27. Riley, R. T., W. P. Norred, E. Wang, and A. H. Merrill. 1999. Alteration in sphingolipid metabolism: bioassays for fumonisin- and ISP-I-like activity in tissues, cells and other matrices. Nat Toxins 7: 407-414.

28. Miyake, Y., Y. Kozutsumi, S. Nakamura, T. Fujita, and T. Kawasaki. 1995. Serine palmitoyltransferase is the primary target of a sphingosine-like immunosuppressant, ISP-1/myriocin. Biochem Biophys Res Commun 211: 396-403.

29. Wang, E., W. P. Norred, C. W. Bacon, R. T. Riley, and A. H. Merrill, Jr. 1991. Inhibition of sphingolipid biosynthesis by fumonisins. Implications for diseases associated with Fusarium moniliforme. J Biol Chem 266: 14486-14490.

30. Williams, L. D., F. I. Meredith, and R. T. Riley. 2004. Fumonisin-ortho-phthalaldehyde derivative is stabilized at low temperature. J Chromatogr B Analyt Technol Biomed Life Sci 806: 311 314. 


\section{Figure legends}

Figure 1: Reduction of palmitoyl-CoA as a side reaction in the presence of different DTT concentrations. The release of free CoA was monitored via the pyruvate dehydrogenase reaction as described under experimental procedures.

Figure 2: (A) SPT and acyl-CoA thioesterase activities in total lysate and microsomes prepared from HEK293 cells in the presence and absence of $0.1 \%$ SML. Low SPT activity and high thioesterase activities were seen in total lysate in the absence of SML. The addition of $0.1 \%$ SML increased SPT activity 6-fold and reduced acyl-CoA thioesterase activities by $90 \%$. SPT activity in total lysate in the presence of $0.1 \%$ SML was similar to the activity in microsomes. The addition of $0.1 \%$ SML to the microsomal preparation did not further improve SPT activity. (B) The SPT reaction in microsomes and total cell lysate $+0.1 \%$ SML was linear over $60 \mathrm{~min}$. SPT activity in total cell lysate is reduced by $80 \%$ in the absence of SML.

SPT activity was assayed using $\left[{ }^{14} \mathrm{C}\right]-\mathrm{L}-$ serine as described in the appendix. For comparability, the activities were normalised to total amount of extracted protein. $n=3$

Figure 3: Influence of substrate concentration on SPT activity. SPT activity was determined using the HPLC-based assay as described in the appendix. For (A) palmitoyl-CoA concentrations were kept at 50 $\mu \mathrm{M}$ and for (B) L-serine concentrations were kept at $2 \mathrm{mM}$. Error bars indicate standard deviation. $n=3$

Figure 4: HPLC chromatograms of threo-sphinganine (thr-Sa), erythro-sphinganine (ery-Sa) and $\mathrm{C}_{20^{-}}$ sphingosine (C20). (A) Standard solutions: 100 pmol threo- / erythro-sphinganine and $100 \mathrm{pmol} \mathrm{C}_{20^{-}}$ sphingosine. (B) Chromatograms of a SPT activity assay with (dashed line) and without (solid line) the addition of $\mathrm{NaBH}_{4}$. (C) Overview of the SPT reaction and the following reduction of 3ketodihydrosphingosine (3KDS) to sphinganine.

Figure 5: Limit of detection (LOD) and correlation. (A) For a maximal assay variance of $20 \%$ (dotted line) the HPLC method had a LOD of $0.1 \mathrm{pmol} / \mathrm{min}$, and the $\left[{ }^{14} \mathrm{C}\right]-\mathrm{L}$-serine based assay a LOD of 2 $\mathrm{pmol} / \mathrm{min}$. The HPLC-based detection was therefore about twenty times more sensitive compared to the 
radioactive assay. (B) Correlation of the radioactivity- and HPLC-based detection method. Activity assay was performed according to the method described in the appendix followed by the addition of $\mathrm{NaBH}_{4}$. The final chloroform phase was split and either analysed on the scintillation counter or by the described HPLC method. Both methods showed a close linear correlation with a correlation coefficient of $r^{2}=0.9519$ 
Table 1: Specific serine palmitoyltransferase activity in various lysate preparations of HEK293 cells. Activities were determined using the radioactivity-based assay. (SML: sucrose monolaurate)

\begin{tabular}{llrr}
\hline Cell preparation & $\begin{array}{l}\text { Thioesterase } \\
\text { inhibitor }\end{array}$ & $\begin{array}{l}\text { SPT activity } \\
\text { [pmol/min/mg total protein }]^{\mathrm{a}}\end{array}$ \\
\hline & & & \\
Total cell lysate & none & $2.4 \pm 0.3^{\mathrm{b}}$ & $2.4 \pm 0.3^{\mathrm{c}}$ \\
& $0.1 \% \mathrm{SML}$ & $12.4 \pm 1.6^{\mathrm{b}}$ & $12.4 \pm 1.6^{\mathrm{c}}$ \\
\hline Microsomes & none & $14.0 \pm 2.8^{\mathrm{b}}$ & $50.3 \pm 10.2^{\mathrm{c}}$ \\
& $0.1 \% \mathrm{SML}$ & $12.9 \pm 1.2^{\mathrm{b}}$ & $46.5 \pm 4.4^{\mathrm{c}}$ \\
\hline Supernatant $\left(100^{\prime} 000 \mathrm{~g}\right)$ & none & not assayed & not assayed \\
& $0.1 \% \mathrm{SML}$ & $0.3 \pm 0.4^{\mathrm{b}}$ & $0.5 \pm 0.6^{\mathrm{c}}$ \\
\hline
\end{tabular}

${ }^{\text {a }}$ Mean \pm standard deviation, $n=3$

${ }^{\mathrm{b}}$ SPT activity normalised to the total amount of extracted protein

${ }^{\mathrm{c}}$ SPT activity normalised to protein amount of the assayed fraction 
Figure 1

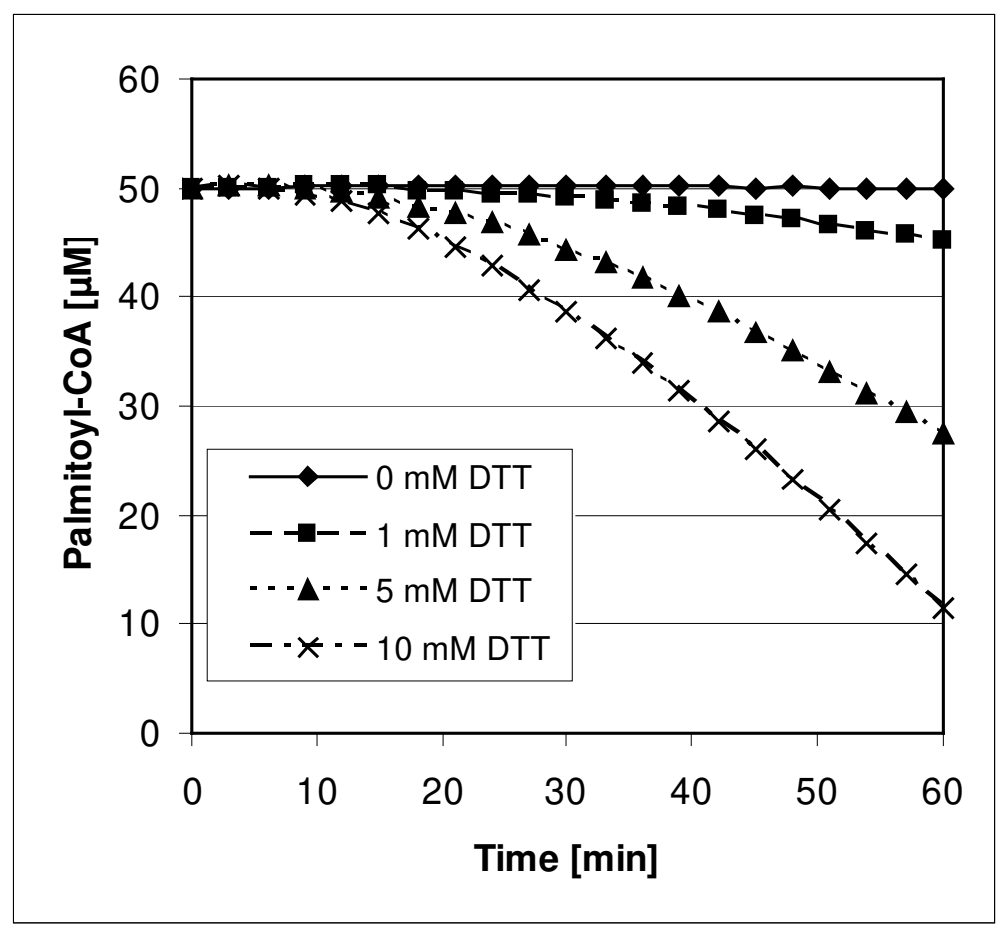

$\Longrightarrow$ 
Figure 2
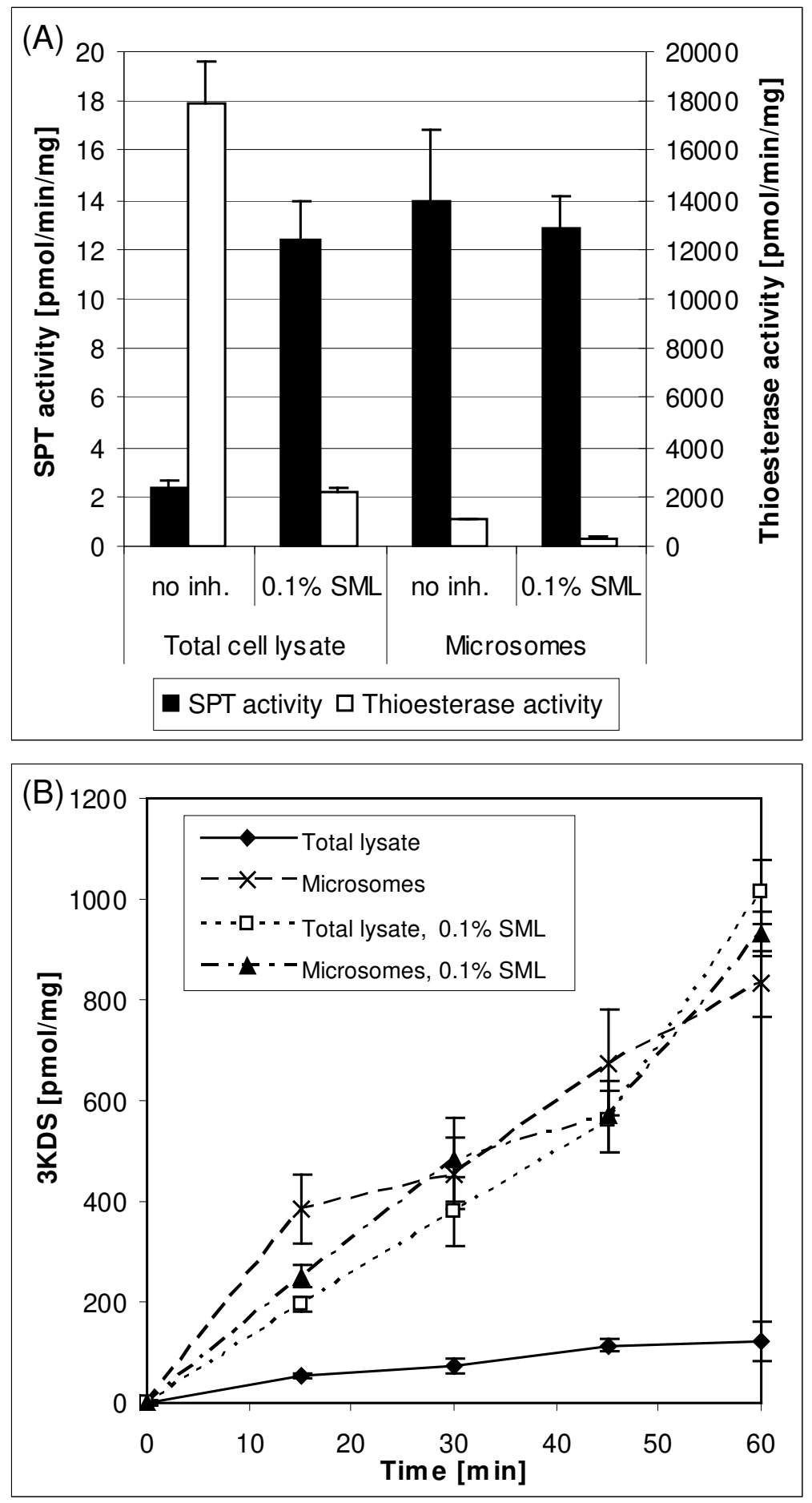
Figure 3
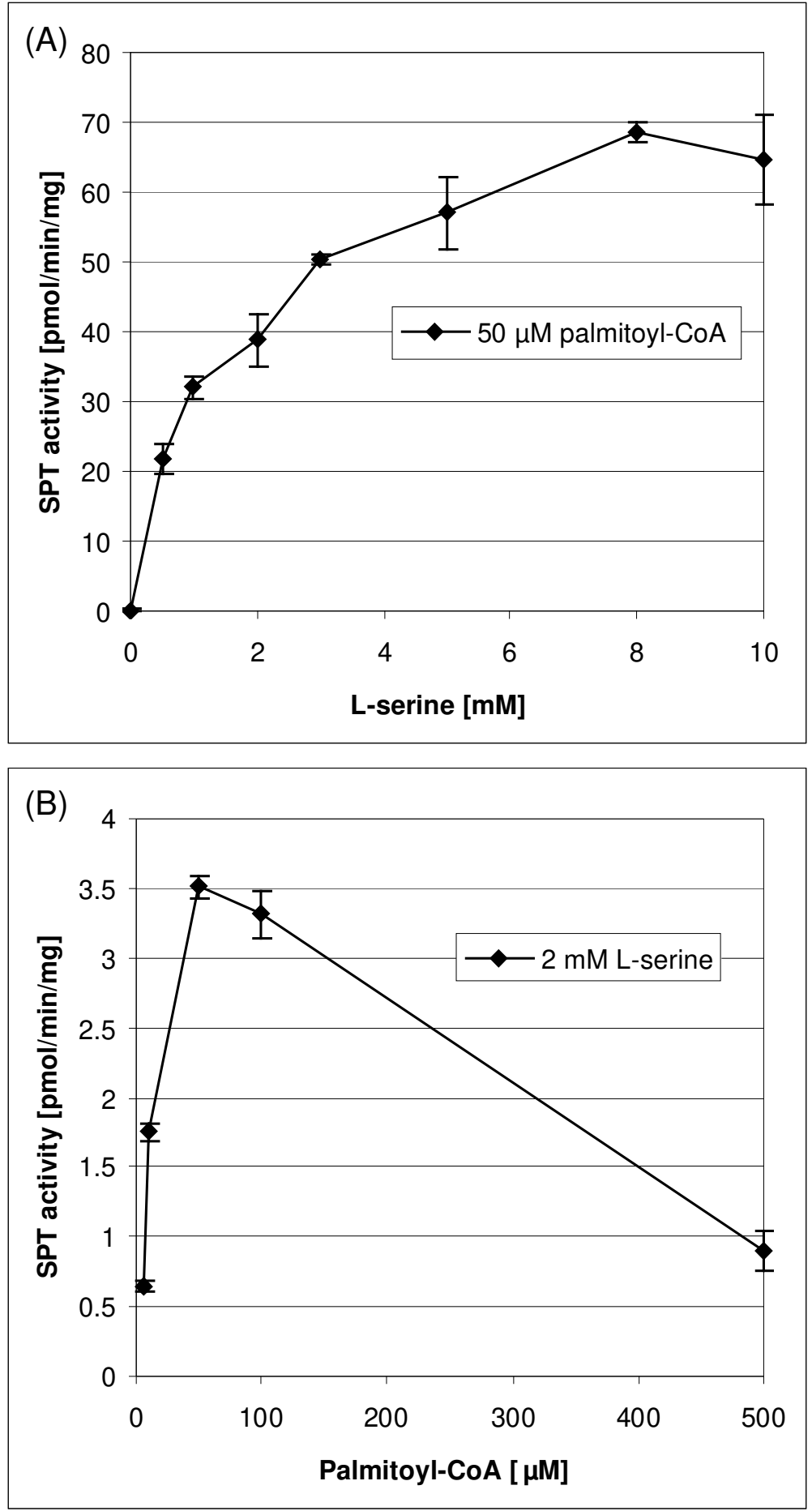
Figure 4

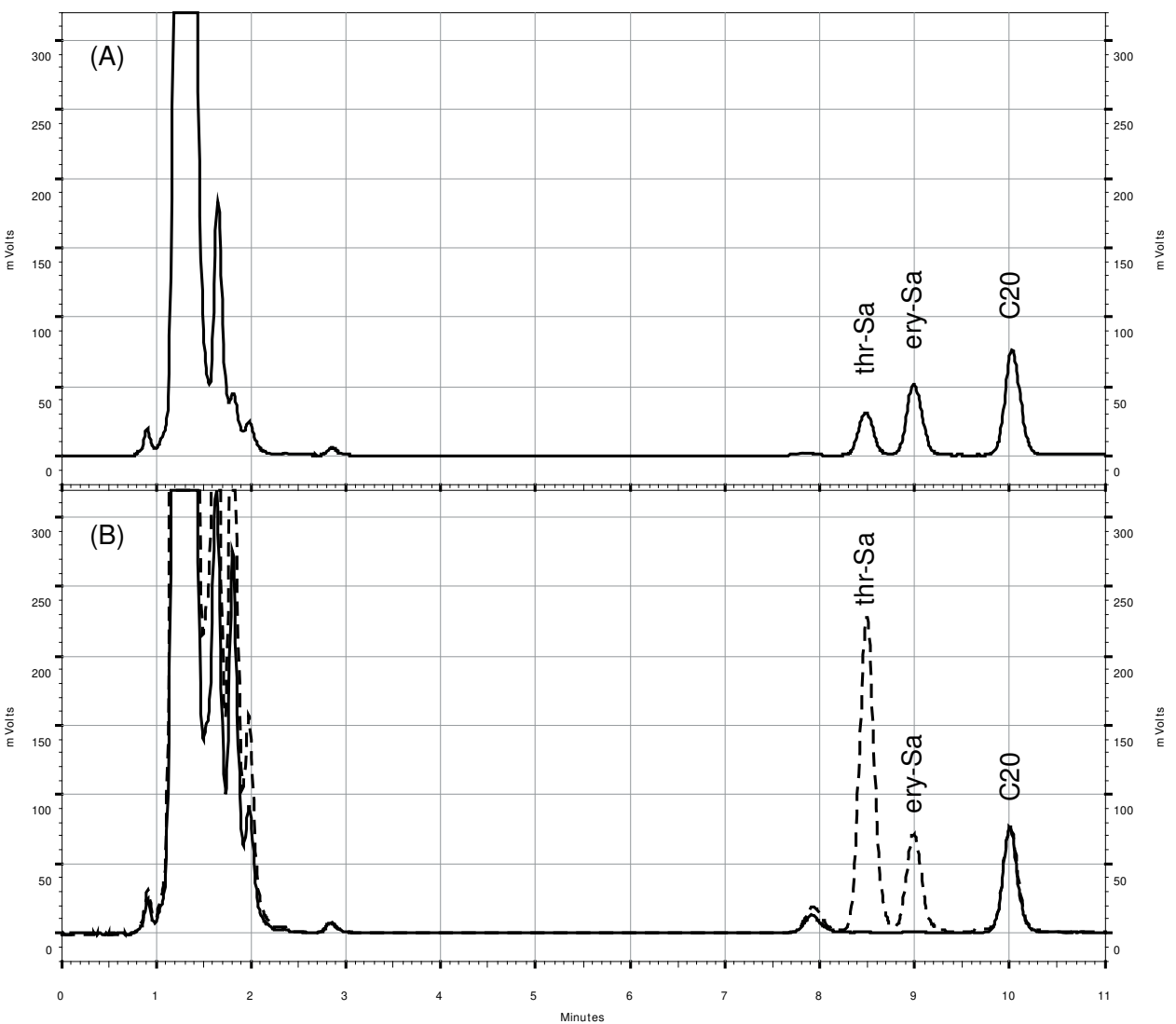

(C)

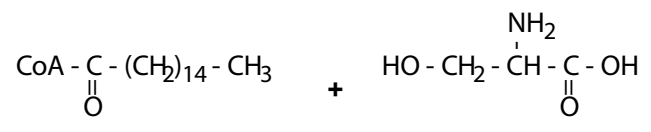

$$
\begin{aligned}
& \text { Palmitoyl-CoA L-serine } \\
& \downarrow \text { SPT }
\end{aligned}
$$

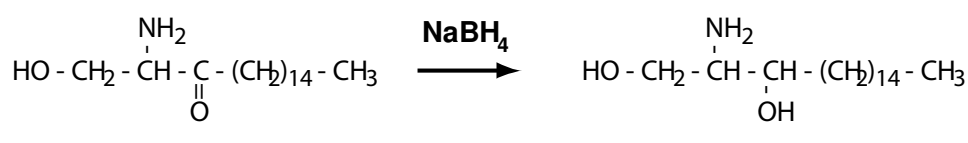

$$
\begin{aligned}
& \text { 3-ketodihydrosphingosine } \\
& \text { Sphinganine }
\end{aligned}
$$


Figure 5
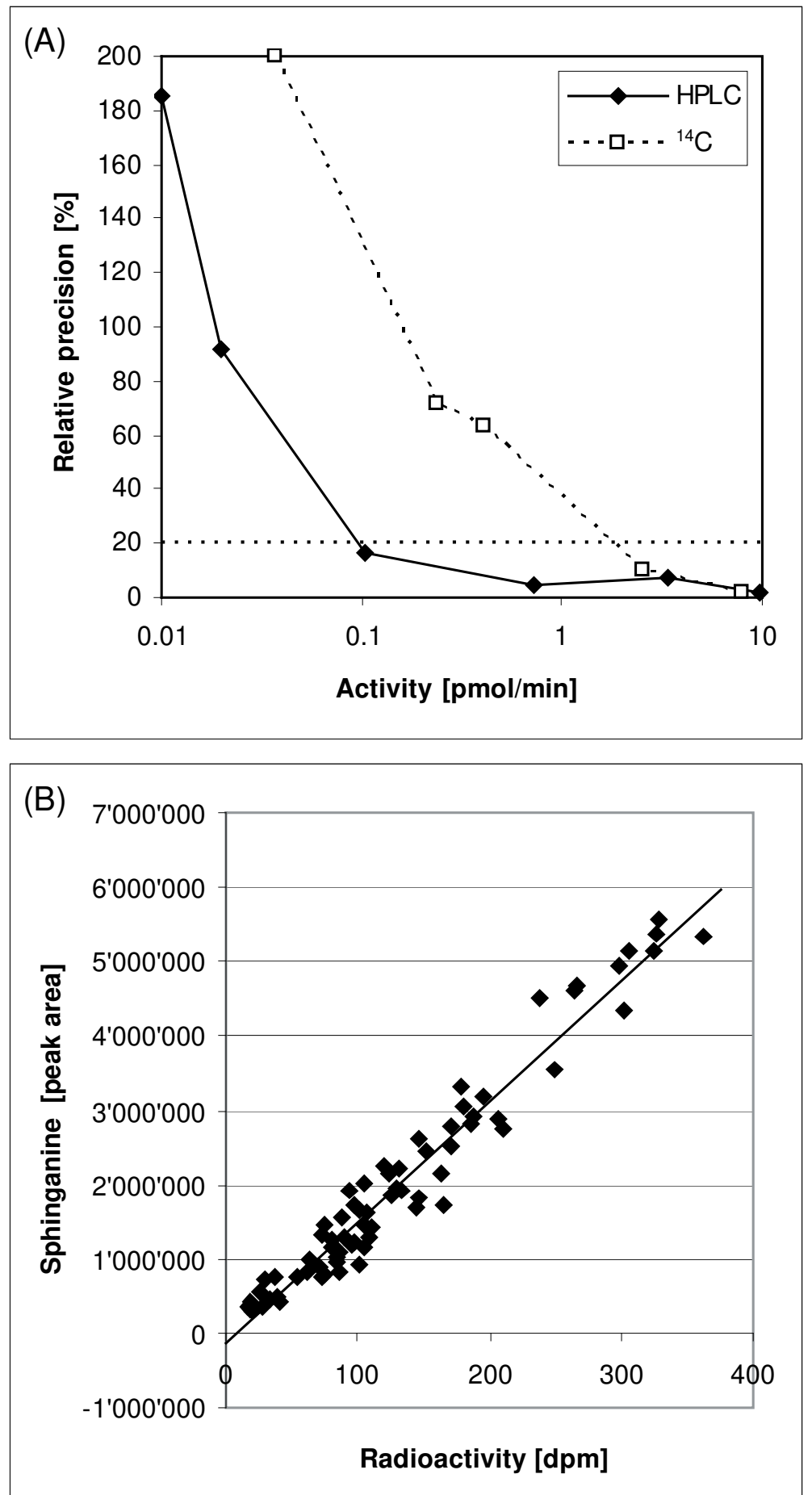


\section{Appendix: Sample protocol for an improved serine palmitoyltransferase activity assay}

This protocol describes an improved assay to determine serine palmitoyltransferase activity. Two different detection methods are suggested:

- Radioactivity-based assay: $\left[{ }^{14} \mathrm{C}\right]$-labelled L-serine is incorporated into 3-ketodihydrosphingosine, which is quantified by liquid scintillation counting.

- HPLC-based assay: 3-ketodihydrosphingosine is chemically reduced by $\mathrm{NaBH}_{4}$ to threo- and erythro-sphinganine, whose ortho-phthalaldehyde derivatives are separated by HPLC and quantified by fluorescence detection.

Reaction conditions:

- Reaction buffer: $50 \mathrm{mM}$ HEPES (pH 8) containing $1 \mathrm{mM}$ EDTA and $0.1 \%$ (wt/vol) sucrose monolaurate

- $5 \mathrm{mM} \mathrm{L-serine} \mathrm{(HPLC-based} \mathrm{assay)} \mathrm{or} 0.5 \mathrm{mM} \mathrm{L-serine} \mathrm{(radioactivity} \mathrm{based} \mathrm{assay)}$

- $\quad 50 \mu \mathrm{M}$ palmitoyl-CoA

- $\quad 20 \mu \mathrm{M}$ pyridoxal 5'-phosphate

\section{General Reagents}

a. Stock solutions: L-serine (200 mM), palmitoyl-CoA (5 mM), pyridoxal 5'-phosphate (5 mM), HEPES-NaOH (0.5 M, pH 8), EDTA (0.5 M, pH 8), sucrose monolaurate (10\% (wt/vol)), myriocin solution $\left(1 \mathrm{mg} / \mathrm{ml}\right.$ in methanol), $\mathrm{NH}_{4} \mathrm{OH}(2 \mathrm{~N})$

b. Alkaline water: $0.1 \mathrm{ml} \mathrm{NH}_{4} \mathrm{OH}(2 \mathrm{~N})$ in $100 \mathrm{ml}$ of water

c. Methanolic KOH: Dissolve $0.7 \mathrm{~g} \mathrm{KOH}$ (platelets) in $100 \mathrm{ml}$ of methanol.

d. Methanol/KOH: $\mathrm{CHCl}_{3}$ (4:1): Mix 4 vol of methanolic $\mathrm{KOH}$ with 1 vol of $\mathrm{CHCl}_{3}$; prepare fresh immediately before use.

e. Lysis buffer: Mix $1 \mathrm{ml}$ of HEPES-NaOH ( $0.5 \mathrm{M}, \mathrm{pH} 8), 20 \mu \mathrm{l}$ of EDTA (0.5 M, pH 8) and $100 \mu 1$ of sucrose monolaurate $(10 \%(\mathrm{wt} / \mathrm{vol}))$. Bring to a volume of $10 \mathrm{ml}$ with water. 
The following reagents are only required for the radioactivity-based assay:

f. $\quad \underline{\mathrm{L}-\left[\mathrm{U}-{ }^{14} \mathrm{C}\right] \text {-serine }(50 \mu \mathrm{Ci} / \mathrm{ml})}$

g. $20 \mathrm{x}\left[{ }^{14} \mathrm{C}\right]$ assay mix (incl. $\left[{ }^{14} \mathrm{C}\right]$-L-serine): example for $250 \mu 1$ (suitable for 25 samples):

Mix $12.5 \mu 1$ of L-serine (200 mM), $20 \mu 1$ of pyridoxal 5'-phosphate ( $5 \mathrm{mM}), 50 \mu 1$ of palmitoyl$\operatorname{CoA}(5 \mathrm{mM}), 100 \mu \mathrm{l}$ of $\mathrm{L}-\left[\mathrm{U}-{ }^{14} \mathrm{C}\right]$-serine $(50 \mu \mathrm{Ci} / \mathrm{ml})$ and $68 \mu 1$ of water.

h. Liquid scintillation cocktail (e.g. Ultima Gold, PerkinElmer)

The following reagents are only required for the HPLC-based assay:

i. 20x HPLC assay mix: example for $250 \mu 1$ (suitable for 25 samples):

Mix $125 \mu$ l of L-serine (200 mM), $20 \mu$ l of pyridoxal 5'-phosphate $(5 \mathrm{mM}), 50 \mu 1$ of palmitoyl$\mathrm{CoA}(5 \mathrm{mM})$, and $55 \mu 1$ of water.

j. $\mathrm{NaBH}_{4}(5 \mathrm{mg} / \mathrm{ml}$ in water $)$ : Prepare immediately before use.

k. Sphingolipid standard solutions: $\mathrm{C}_{17}$-sphingosine ( $1 \mathrm{mM}$ in ethanol), threo- / erythro-sphinganine (1 $\mathrm{mM}$ in ethanol)

1. HPLC standard mix: Mix $5 \mu 1$ of $\mathrm{C}_{17}$-sphingosine ( $1 \mathrm{mM}$ in ethanol) and $5 \mu 1$ of threo- / erythrosphinganine (1 $\mathrm{mM}$ in ethanol). Bring to a volume of $7.5 \mathrm{ml}$ with methanol:ethanol:water $(85: 47.5: 17.5)$.

m. Methanol: $\mathrm{CHCl}_{2}: 0.1 \mathrm{M} \mathrm{KOH}+\mathrm{C}_{17}$-Sphingosine (internal standard): Add $0.2 \mu 1$ of $\mathrm{C}_{17^{-}}$ sphingosine (1 mM in ethanol) per $\mathrm{ml}$ methanol/KOH: $\mathrm{CHCl}_{3} .0 .5 \mathrm{ml}$ is needed per sample. Prepare always fresh immediately before use.

n. Boric acid (3\% (wt/vol), $\mathrm{pH} 10.5)$ : Adjust $\mathrm{pH}$ with $\mathrm{KOH}$ as necessary. Check $\mathrm{pH}$ before use.

o. Ortho-phthalaldehyde (OPA, $50 \mathrm{mg} / \mathrm{ml}$ in ethanol)

p. OPA reagent: Mix $10 \mu \mathrm{lOPA}(50 \mathrm{mg} / \mathrm{ml}$ in ethanol), $990 \mu \mathrm{l}$ boric (3\% (wt/vol), $\mathrm{pH} 10.5))$ and $0.5 \mu 1$ of 2-mercaptoethanol. Store in dark, $4{ }^{\circ} \mathrm{C}$. Prepare fresh daily.

q. Potassium phosphate buffer (5mM, pH 7): Mix $5 \mathrm{mM} \mathrm{K}_{2} \mathrm{HPO}_{4}(0.87 \mathrm{~g}$ in $1000 \mathrm{ml}$ of water) and 5 $\mathrm{mM} \mathrm{KH}{ }_{2} \mathrm{PO}_{4}(0.68 \mathrm{~g}$ in $1000 \mathrm{ml}$ of water) in a ratio of $61: 39$ (vol/vol) and adjust $\mathrm{pH}$ as necessary.

r. Running buffer for HPLC: methanol:5 mM potassium phosphate buffer ( $\mathrm{pH} 7)(90: 10, \mathrm{vol} / \mathrm{vol})$ 


\section{Preparation of total cell lysate}

All steps at $4{ }^{\circ} \mathrm{C}$

a. Cell monolayer in a $10-\mathrm{cm}$ dish ( $80-90 \%$ confluent $)$

b. After washing twice with PBS, suspend cells in $1 \mathrm{ml}$ of lysis buffer.

c. Sonicate for $15 \mathrm{~s}$ at $50 \%$ power and $50 \%$ pulsation. Solution should be homogeneous. No clumps should be visible.

d. Centrifuge at $2,500 \mathrm{~g}$ for $2 \mathrm{~min}$ to remove debris.

e. Take supernatant and determine protein concentration. Total protein concentration should be around $2 \mathrm{mg} / \mathrm{ml}$. Dilute with lysis buffer if desired.

\section{SPT activity assay}

Do the reaction in a $2 \mathrm{ml}$ polypropylene reaction tube.

a. Take $190 \mu 1$ of total cell lysate (about $200-400 \mu \mathrm{g}$ total protein) and $10 \mu \mathrm{l}$ of the corresponding 20x assay mix $\left(\left[{ }^{14} \mathrm{C}\right]\right.$ or HPLC). Vortex briefly and keep samples on ice. For negative control, add $2 \mu 1$ of myriocin solution. To correct for a methanol effect also add $2 \mu 1$ of methanol to the samples.

b. To start the reaction transfer tubes to a water bath. Incubate at $37{ }^{\circ} \mathrm{C}$ for $60 \mathrm{~min}$.

The following step is only necessary for the HPLC-based assay:

c. Add $50 \mu 1$ of $\mathrm{NaBH}_{4}(5 \mathrm{mg} / \mathrm{ml})$ and let react for $5 \mathrm{~min}$ at room temperature.

\section{Lipid extraction and product detection}

a. Add $0.5 \mathrm{ml}$ of methanol/ $\mathrm{KOH}: \mathrm{CHCl}_{3}$ (for the radioactivity-based assay) or $0.5 \mathrm{ml}$ of methanol: $\mathrm{CHCl}_{3}: 0.1 \mathrm{M} \mathrm{KOH}+\mathrm{C}_{17}$-sphingosine (for the HPLC-based assay) and mix intensively (vortex).

b. Add $0.5 \mathrm{ml} \mathrm{CHCl}_{3}$.

c. Add $0.5 \mathrm{ml}$ alkaline water and $100 \mu \mathrm{l}$ of $2 \mathrm{~N} \mathrm{NH}_{4} \mathrm{OH}$, mix intensively (vortex).

d. Centrifuge (12’000g, $1 \mathrm{~min}$ at room temperature).

e. Remove the upper phase with gentle aspiration. 
f. Wash the lower phase twice with $900 \mu \mathrm{l}$ of alkaline water.

The following steps are only necessary for the radioactivity-based assay:

g. Transfer $400 \mu$ of the lower phase to a polyethylene scintillation vial.

h. Let the $\mathrm{CHCl}_{3}$ evaporate under a stream of nitrogen.

i. Add $5 \mathrm{ml}$ of liquid scintillation cocktail and count the incorporated radioactivity by a scintillation counter. For activity calculations take into account that the transferred $400 \mu 1 \mathrm{CHCl}_{3}$ are $2 / 3$ of the total $\mathrm{CHCl}_{3}$ phase $(600 \mu \mathrm{l})$.

The following steps are only necessary for the HPLC-based assay:

j. Transfer $400 \mu 1$ of the lower phase to a new $2 \mathrm{ml}$ polypropylene vial.

k. Let the $\mathrm{CHCl}_{3}$ evaporate under a stream of nitrogen.

1. Re-dissolve the residue in $150 \mu 1$ of methanol:ethanol: $\mathrm{H}_{2} \mathrm{O}(85: 47.5: 17.5)$.

m. In an additional vial, add $150 \mu 1$ of HPLC standard mix. This vial will provide the defined standard peaks.

n. Add $5 \mu 1$ of OPA reagent to each vial and let react for $2 \mathrm{~h}$ in the dark.

o. Analyse samples by HPLC using the following conditions:

- C18 reverse-phase column (100 Å pore size, $3 \mu \mathrm{m}$ particle size, $4 \times 125 \mathrm{~mm}$ column)

- Injection volume: $50 \mu 1$

- Flow rate: $1.0 \mathrm{ml} / \mathrm{min}$

- Pump program:

- 0 - 20 min: methanol:5 mM potassium phosphate buffer ( $\mathrm{pH} 7)(90: 10, \mathrm{vol} / \mathrm{vol})$, isocratic

- 20 - 25 min: methanol (100\%), isocratic (wash)

- 25 - 30 min: methanol:5 mM potassium phosphate buffer (pH 7) (90:10, vol/vol), isocratic

- Measure OPA fluorescence at an excitation wavelength of $335 \mathrm{~nm}$ and an emission wavelength of $440 \mathrm{~nm}$.

p. Retention times for $\mathrm{C}_{17}$-sphingosine, threo- and erythro-sphinganine standards are approximately 5.5, 8.5 and $9 \mathrm{~min}$. 
q. SPT activity is calculated using the following formula:

$$
v=\left(\left(t h r_{\text {sample }}+e r y_{\text {sample }}\right) \times C 17_{\text {std }} \times 100 \mathrm{pmol}\right) /\left(\left(t h r_{\text {std }}+\text { ery }_{\text {std }}\right) \times C 17_{\text {sample }} \times p_{\text {tot }} \times t\right)
$$

Where $v$ is the specific SPT activity in $\mathrm{pmol} / \mathrm{min} / \mathrm{mg}$, thr and ery are the areas of threo- and erythro-sphinganine peaks, $C 17$ is the area of $\mathrm{C}_{17}$-sphingosine peak, $p_{t o t}$ is the total amount of

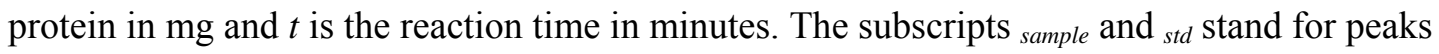
from the samples and from the HPLC standard mix, respectively. 